\title{
Proximity of public elementary schools to major roads in Canadian urban areas
}

\author{
Ofer Amram', Rebecca Abernethy ${ }^{2}$, Michael Brauer ${ }^{2}$, Hugh Davies $^{2}$ and Ryan W Allen ${ }^{3 *}$
}

\begin{abstract}
Background: Epidemiologic studies have linked exposure to traffic-generated air and noise pollution with a wide range of adverse health effects in children. Children spend a large portion of time at school, and both air pollution and noise are elevated in close proximity to roads, so school location may be an important determinant of exposure. No studies have yet examined the proximity of schools to major roads in Canadian cities.

Methods: Data on public elementary schools in Canada's 10 most populous cities were obtained from online databases. School addresses were geocoded and proximity to the nearest major road, defined using a standardized national road classification scheme, was calculated for each school. Based on measurements of nitrogen oxide concentrations, ultrafine particle counts, and noise levels in three Canadian cities we conservatively defined distances $<75 \mathrm{~m}$ from major roads as the zone of primary interest. Census data at the city and neighborhood levels were used to evaluate relationships between school proximity to major roads, urban density, and indicators of socioeconomic status.
\end{abstract}

Results: Addresses were obtained for 1,556 public elementary schools, 95\% of which were successfully geocoded. Across all 10 cities, $16.3 \%$ of schools were located within $75 \mathrm{~m}$ of a major road, with wide variability between cities. Schools in neighborhoods with higher median income were less likely to be near major roads (OR per $\$ 20,000$ increase: $0.81 ; 95 \% \mathrm{Cl}: 0.65,1.00$ ), while schools in densely populated neighborhoods were more frequently close to major roads (OR per 1,000 dwellings/ $\left.\mathrm{km}^{2}: 1.07 ; 95 \% \mathrm{Cl}: 1.00,1.16\right)$. Over $22 \%$ of schools in the lowest neighborhood income quintile were close to major roads, compared to $13 \%$ of schools in the highest income quintile.

Conclusions: A substantial fraction of students at public elementary schools in Canada, particularly students attending schools in low income neighborhoods, may be exposed to elevated levels of air pollution and noise while at school. As a result, the locations of schools may negatively impact the healthy development and academic performance of a large number of Canadian children.

\section{Introduction}

Motor vehicles are a major source of both air and noise pollution in communities. Epidemiologic studies have linked exposure to traffic-generated air pollution with a wide range of adverse effects in children including reduced lung function [1], decrements in lung growth [2], incident asthma [3], otitis media [4], and decreased cognitive function [5]. Chronic exposure to traffic noise among children has been linked with increased blood pressure [6], reduced sleep quality [7], and cognitive deficits [8].

\footnotetext{
* Correspondence: allenr@sfu.ca

${ }^{3}$ Faculty of Health Sciences, Simon Fraser University, Burnaby, BC, Canada Full list of author information is available at the end of the article
}

For children, school is an important environment for exposure to traffic-related pollution due to the amount of time spent there [9]. According to the Canadian Human Activity Pattern Survey, children 11-17 years spend an average of $12 \%$ of time of their time at school, making it the second most common microenvironment, while for children $<11$ years school is the $3^{\text {rd }}$ most important microenvironment, accounting for $6 \%$ of time on average [10]. Both noise and traffic-generated air pollutants such as diesel soot, ultrafine particles, oxides of nitrogen $\left(\mathrm{NO}_{\mathrm{x}}\right)$, and carbon monoxide are elevated within approximately 100-500 meters of major roadways [11-15], so the proximity of schools to major roads may be an important determinant of exposure. A study in the Netherlands found that

\section{Biomed Central}


for children attending a school within $100 \mathrm{~m}$ of a freeway, soot exposure was $30 \%$ higher and $\mathrm{NO}_{\mathrm{x}}$ exposure was $37 \%$ higher than among children attending a school in a background location [16]. Students attending schools close to major roads can be exposed to traffic-related air pollution even while indoors because outdoor pollution infiltrates into classrooms $[17,18]$. Inverse correlations between concentrations of traffic-related air pollution inside classrooms and distance to the nearest major road have been reported $[19,20]$.

Several studies have quantified the distances from schools to major roads in the US [21-24], but no results for schools in other countries have been published. Here we present the results from an investigation of the roadway proximities of public elementary schools in the ten largest Canadian cities. Our objectives were to: 1 ) validate the use of roadway proximity as a surrogate for outdoor concentrations of traffic-generated air and noise pollution using measurements from previous field studies; 2) determine the proximities of public schools to major roads; and 3) explore urban characteristics and socio-economic indicators as correlates of schools' proximities to major roads.

\section{Methods}

\section{Schools Data}

Public elementary schools for the 10 most populated cities in Canada were chosen for this analysis as children in this age group may be particularly susceptible to the effects of environmental pollutants. Elementary schools were defined as those with students in kindergarten through grade 5 (schools with students in other grades were included if their enrollment also included students in grades of interest). We included only public schools due primarily to concerns about the quality and completeness of private school data in provincial databases. In addition, only about $6 \%$ of Canadian students attend private schools [25]. Cities from five provinces were included in the analysis. In Ontario: Toronto, Hamilton, Mississauga and Ottawa; in Quebec: Montreal and Quebec City; in Alberta: Calgary and Edmonton; in British Columbia: Vancouver; and in Manitoba: Winnipeg. For each city we only included schools within the municipality as defined by the census subdivision (i.e., we did not include schools in suburban communities). We included only urban areas primarily due to their higher levels of traffic-related air pollution and noise and concerns about geocoding accuracy in low density communities [26,27]. In addition, the majority of pollution measurements used to validate road proximity as a surrogate for pollution levels (described below) were collected in urban areas. To evaluate the sensitivity of our results to the exclusion of suburban communities, we randomly selected one census subdivision adjacent to each of five of our cities and geocoded the locations of schools in those five suburbs (the adjacent census subdivisions were Burlington, Brampton, Laval, Markham, and Richmond; these are adjacent to Hamilton, Mississagua, Montreal, Toronto, and Vancouver, respectively).

Relevant school attributes included the address, grade levels and type of school (public, private or other). As information regarding Canadian educational institutions is not centrally collected, the majority of this information resides with the provincial Ministries of Education (MoE). As a result, the availability and format of these data differ by province. Public school locations were collected using data available from the MoE websites for each province [see Additional file 1].

\section{School Geocoding and Road Proximity Calculations}

We used the commercially available DMTI CanMap road network to identify road locations and attributes (DMTI Spatial, Markham, ON). This product covers Canada and divides roads into 6 categories. In our primary analysis we combined DMTI road categories 1 (expressways, usually four lanes), 2 (principal highways, which are multi-lane conduits for intracity traffic), 3 (secondary highways, which are typically thoroughfares with multiple lanes and large traffic capacity), and 4 (major roads, used for shorter trips within the city) into a single layer (henceforth "major roads") for analysis of school proximities [28]. GeoPinPoint (GPP) software, a product of DMTI, was used to geocode school addresses into latitude/longitude coordinates using a $10 \mathrm{~m}$ offset from the road's centerline. Designed for use within Canada, GPP uses the DMTI road network and allows for the geocoding of French-language addresses. In addition, it provides a summary output that details the number of schools successfully geocoded.

After geocoding, we calculated the distance from each school to the nearest major road using ArcGIS 9.2 (ESRI, Redland, CA). As a secondary analysis, we also quantified the distance from each school to the nearest expressway or principal highway (DMTI road categories 1 and 2) to allow for comparisons with previous studies in the US [21-23].

\section{Assessing Geocoding Accuracy}

Because school buildings and grounds cover large areas, and because geocoding of schools can produce substantial location errors [27], we manually determined the locations of a subset of schools for comparison with our automated geocoding results. First, we selected schools with geocoded locations within $200 \mathrm{~m}$ of a major road $(\mathrm{N}=533)$. From these we randomly selected 148 schools ( $10 \%$ of the 1,476 schools in the analysis) while requiring that at least five schools from each city be included. For each of these 148 schools, we then used satellite images from Google Maps to manually determine the coordinates of the point of the school building nearest to a major road and calculated the 
distance from that location to the nearest major road using ArcGIS. The major road proximities assessed by this manual method were considered the "true" distances for comparison with the distances estimated from the GPP geocoding procedure.

\section{Pollution Data}

We used measurements from previous field sampling campaigns in Edmonton, Vancouver, and Winnipeg to validate the assumption that roadway proximity acts as a surrogate for concentrations of traffic-generated air pollution and noise. Nitrogen oxide (NO) concentrations were measured on a 2-week basis using passive Ogawa samplers at 50 locations each in Edmonton and Winnipeg [29] and 105 locations in Vancouver [30]. Locations were selected to cover the study areas and to capture a wide range of road proximities. Each location was monitored twice in different seasons, and the two measurements at each location were combined to estimate the long-term average concentration. Abernethy et al. [31] measured concentrations of ultrafine $(<0.1 \mu \mathrm{m}$ diameter $)$ particles, another traffic-generated air pollutant, for 1-hour periods at 80 of the NO monitoring locations in Vancouver using condensation particle counters (TSI CPC 3007, Shoreview, MN). Measurements were adjusted to account for temporal variation in ultrafine particle concentrations, and comparisons of measurements collected in different seasons suggest that 1-hour measurements represent long-term conditions. Davies et al. [32] measured 5-min equivalent continuous sound pressure levels $\left(\mathrm{L}_{\mathrm{eq}}\right)$ at the NO monitoring locations in Vancouver using a Larson Davis $870 \mathrm{~B}$ sound level meter (Larson Davis, Depew, NY). We have previously shown a strong correlation between 5-min noise levels measured in different seasons [11], suggesting that these measurements are indicative of long-term noise levels. The locations of these NO, ultrafine particle, and noise measurements were recorded by field technicians using GPS. We used ArcGIS to calculate the distance from the measurement locations to the nearest major road, defined using the same DMTI data and road classification scheme as in the school proximity calculations.

\section{Correlates of Road Proximity}

Data from the 2006 Canadian census were used to evaluate the relationship between schools' proximities to major roads and both dwelling density and socio-economic variables. Because we hypothesized that both city- and neighborhood-level characteristics might be correlated with proximity, we obtained data for the census subdivision (CSD) and census tract (CT) in which each school is located. CSD areas correspond to city boundaries, while CTs typically have populations between 2,500 and 8,000 and are useful proxies for neighborhoods in Canada [33]. Specific variables included dwelling density at both the city (CSD) and neighborhood (CT) levels as well as median income and percent of population without a high school diploma or equivalent at the neighborhood level [23]. Socio-economic variables were not considered at the city level because these variables are assumed to be meaningful primarily in the local context and may not be directly comparable between cities due to differences in costs of living or other factors. To account for clustering within cities and neighborhoods, we used mixed models with random intercepts at the city and neighborhood levels. We modeled school proximity as a binary proximity variable with $75 \mathrm{~m}$ cut point (PROC GLIMMIX, SAS v9.2) and also as a continuous variable (PROC MIXED). Although the influence of traffic-generated air pollution and noise extends well beyond $75 \mathrm{~m}$ [14], we chose this distance to be conservative, given geocoding errors and the relatively large areas of schools and playgrounds. To evaluate the sensitivity of model results to the choice of binary distance, we also modeled school proximity as a binary variable using $200 \mathrm{~m}$ cut point. Contrasts in predictor variables were scaled to roughly correspond to interquartile ranges (IQR) to allow for comparisons of effect sizes between variables.

\section{Results}

Addresses were obtained for a total of 1,556 public elementary schools, 1,476 (94.9\%) of which were successfully geocoded into a latitude/longitude location (Table 1). The geocoding success rate in individual cities ranged between $75.7 \%$ (in Calgary) and $100 \%$ (in four cities). Variables affecting geocoding success included addresses with no match in the road network and use of post office boxes as mailing addresses. The populations in the 10 cities included in this analysis ranged between approximately 490,000 in Quebec City and 2.5 million in Toronto [34]. The combined population of these 10 cities was approximately 9.5 million, or nearly one third of the total Canadian population.

Pollution measurements in Edmonton, Vancouver, and Winnipeg were inversely correlated with the natural logarithm of distance to the nearest major road, with stronger correlations in Winnipeg $(r=-0.44 ; \mathrm{p}<0.01)$ and Vancouver $(r=-0.50$ to $-0.61 ; \mathrm{p}<0.01)$ than in Edmonton $(r=-0.27 ; \mathrm{p}=0.06)$. Similar correlations were found when including only measurements within $200 \mathrm{~m}$ of a major road. Based on these measurements we conservatively defined 'near roads' as $<75 \mathrm{~m}$ (Figure 1). Mean ( \pm $\mathrm{SD}) \mathrm{NO}$ concentrations measured $<75 \mathrm{~m}$ from the nearest major road were greater than those measured $\geq 75 \mathrm{~m}$ in both Winnipeg $(14.4 \pm 7.3$ ppb vs. $9.5 \pm 4.2 \mathrm{ppb}$; 2 -sample t-test p-value: $<0.01)$ and Vancouver $(48.1 \pm 20.3 \mathrm{ppb}$ vs. $23.4 \pm 11.3 \mathrm{ppb} ; \mathrm{p}<0.01)$. In Edmonton the difference was less pronounced $(15.6 \pm 7.4 \mathrm{ppb}$ vs. $12.6 \pm 4.1 \mathrm{ppb}$; $\mathrm{p}=0.17)$. Ultrafine particles $(26,000 \pm 18,200 \mathrm{p} / \mathrm{cc}$ vs. 


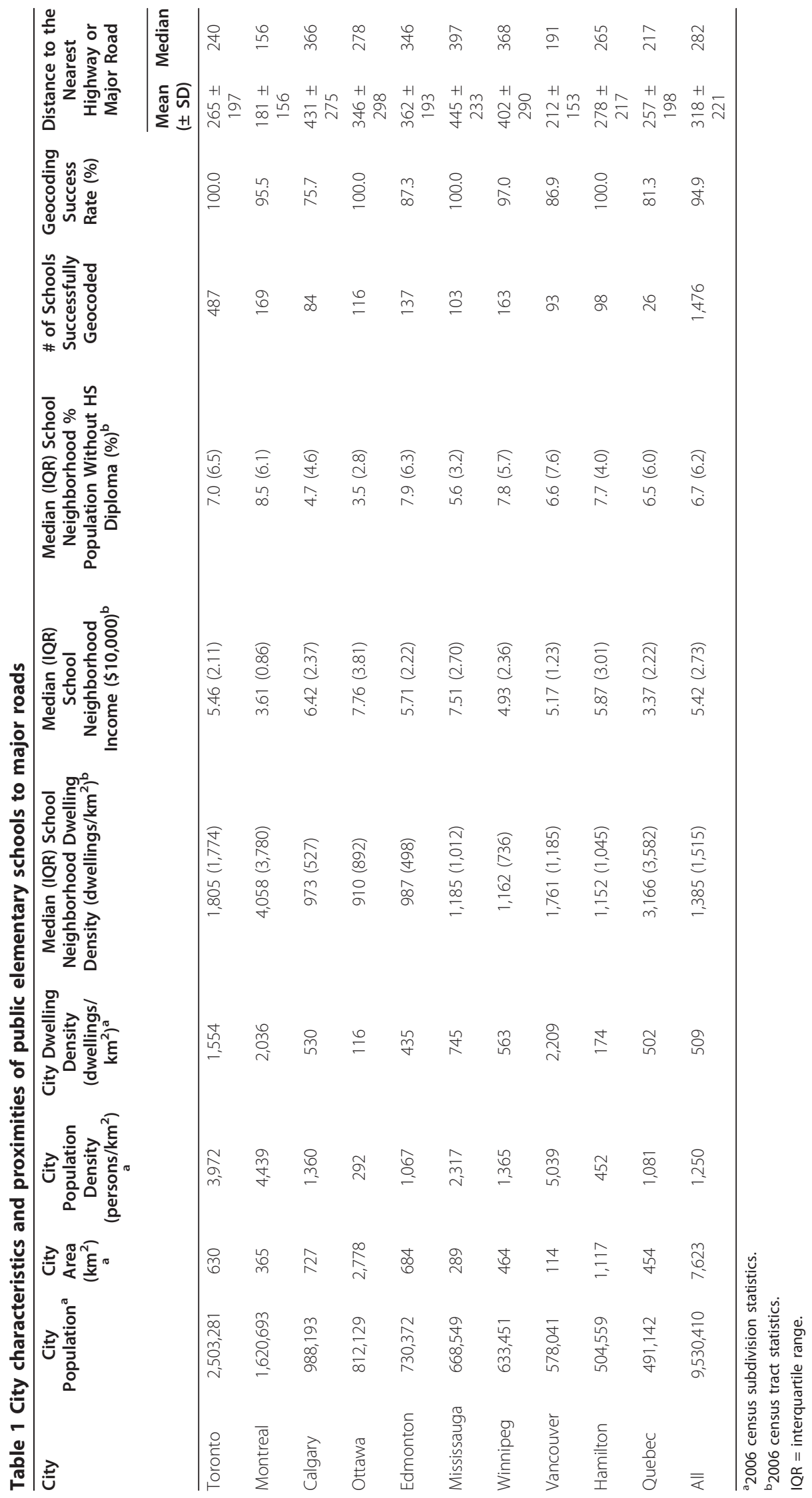




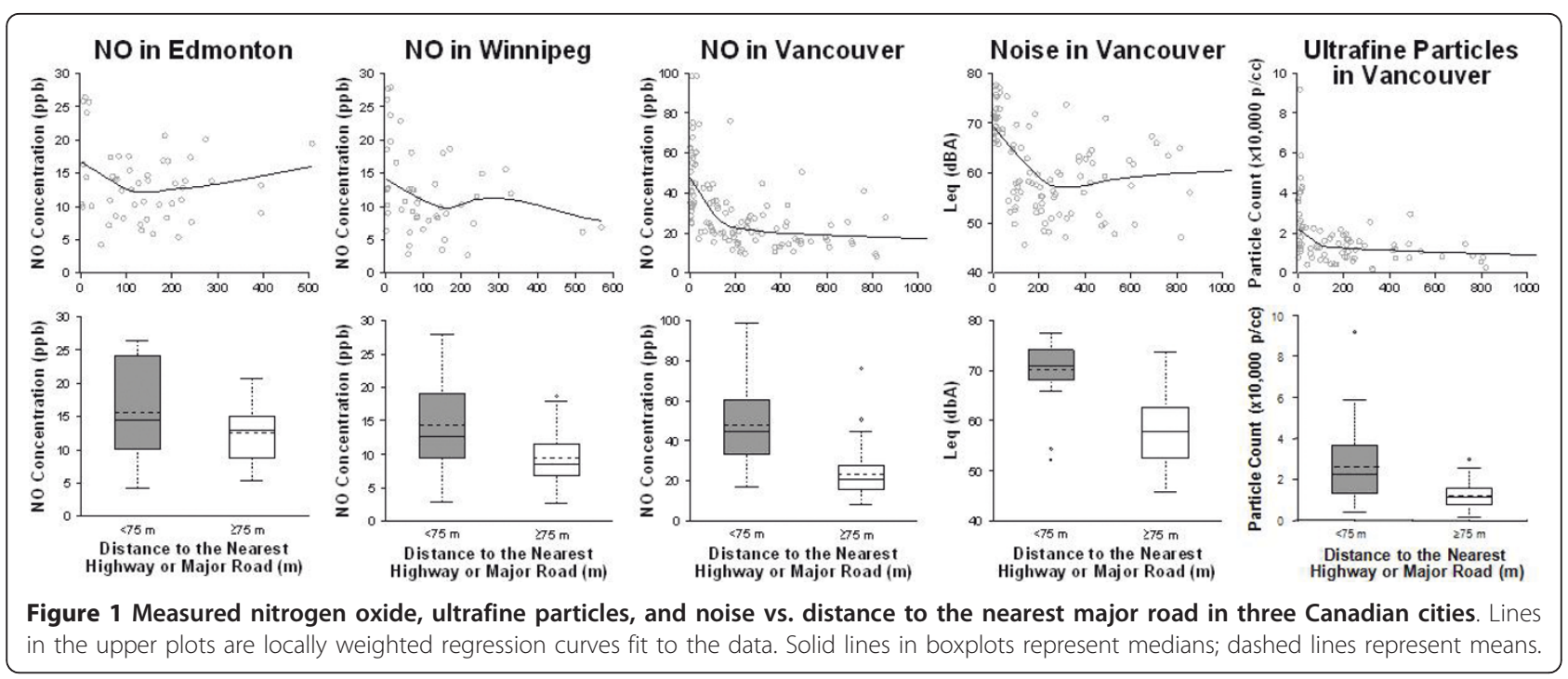

$12,000 \pm 6,200 \mathrm{p} / \mathrm{cc} ; \mathrm{p}<0.01)$ and noise $(70.2 \pm 5.7 \mathrm{dBA}$ vs. $57.9 \pm 6.5 \mathrm{dBA} ; \mathrm{p}<0.01)$ in Vancouver were also significantly elevated within $75 \mathrm{~m}$ of major roads. In fact, in Vancouver the influence of major roads extended to approximately $200 \mathrm{~m}$ (Figure 1 ). Concentrations within $200 \mathrm{~m}$ of a major road were significantly higher than those $\geq 200 \mathrm{~m}$ for NO $(39.7 \pm 20.1 \mathrm{ppb}$ vs. $20.6 \pm 9.1 \mathrm{ppb}$; 2 sample t-test $p$-value: $<0.01)$, ultrafine particles $(21,300 \pm$ $16,300 \mathrm{p} / \mathrm{cc}$ vs. $11,700 \pm 6,400 \mathrm{p} / \mathrm{cc} ; \mathrm{p}<0.01)$, and noise $(65.1 \pm 8.2 \mathrm{dBA}$ vs. $57.2 \pm 6.6 \mathrm{dBA} ; \mathrm{p}<0.01)$.

Across all 10 cities, $16.3 \%$ of schools were located within $75 \mathrm{~m}$ of a major road (Figure 2). There was considerable variability between cities, ranging between $2.9 \%$ of schools in Mississauga, Ontario and 33.7\% in Montreal, Quebec. Using a less conservative cut-off distance of $200 \mathrm{~m}, 36.1 \%$ of schools were located close to a major

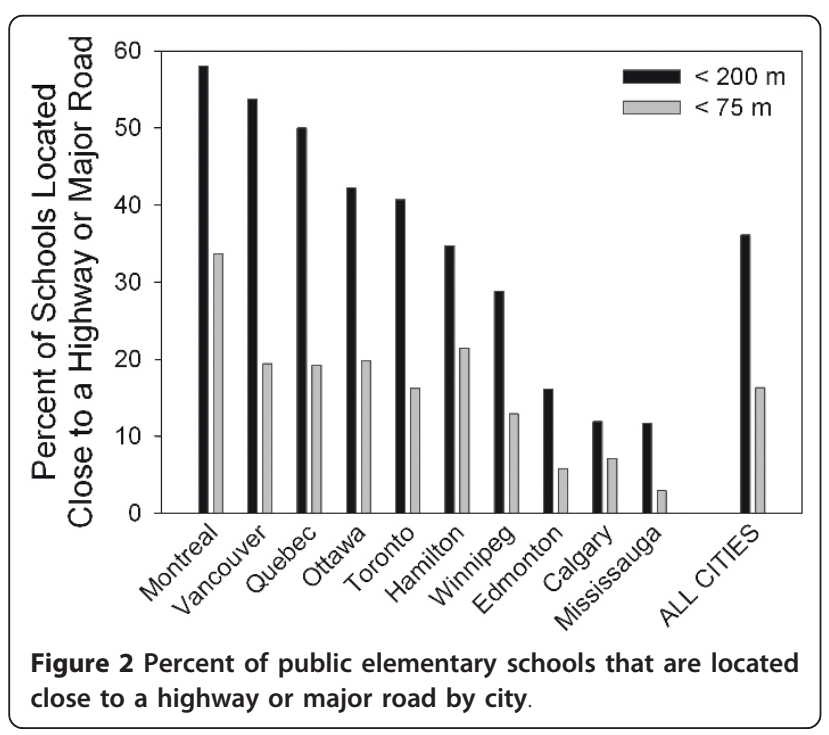

road, ranging between $11.7 \%$ of schools in Mississauga and $58.0 \%$ in Montreal (Figure 2). There was not a strong east-west gradient in school proximities by city. When considering only expressways or principal highways (DMTI road categories 1 and 2) to allow for comparisons with previous studies in the US, we found that $4.7 \%$ of schools were located within $200 \mathrm{~m}$, ranging between $0 \%$ in both Calgary and Hamilton and $16.0 \%$ in Montreal.

Based on comparisons between five cities and communities adjacent to each, we found that a larger percentage of schools included in our analysis were located near major roads than schools in adjacent communities. In Hamilton, Mississauga, Montreal, Toronto, and Vancouver $18.7 \%$ of 950 schools were within $75 \mathrm{~m}$ of a major road, while in the five selected adjacent communities $9.3 \%$ of 236 schools were within $75 \mathrm{~m}$. The cities all had higher percentages of proximate schools than their adjacent communities, with the exception of Mississauga, where the percentage of schools within $75 \mathrm{~m}$ of a major road (2.9\%) was lower than the adjacent community of Brampton (4.1\%).

When modeling schools' proximities to major roads as a binary variable $(<75 \mathrm{~m}$ or $\geq 75 \mathrm{~m})$ we found that both higher neighborhood dwelling density (OR per 1,000 dwellings $/ \mathrm{km}^{2}$ increase: $1.07 ; 95 \%$ CI: $\left.1.00,1.16\right)$ and lower neighborhood median income (OR per $\$ 20,000$ increase: 0.81; $95 \%$ CI: $0.65,1.00)$ were associated with closer school proximity to the nearest major road (Table 2). Similar results were observed when schools were categorized as < $200 \mathrm{~m}$ or $200 \mathrm{~m}$, and when school proximity was modeled as a continuous variable (Table 2). For example, for each $\$ 20,000$ increase in median neighborhood income, schools were an average of $47 \mathrm{~m}(95 \%$ CI: 33, 61) further from major roads. The relationship between neighborhood median income and school proximity to roads is summarized 


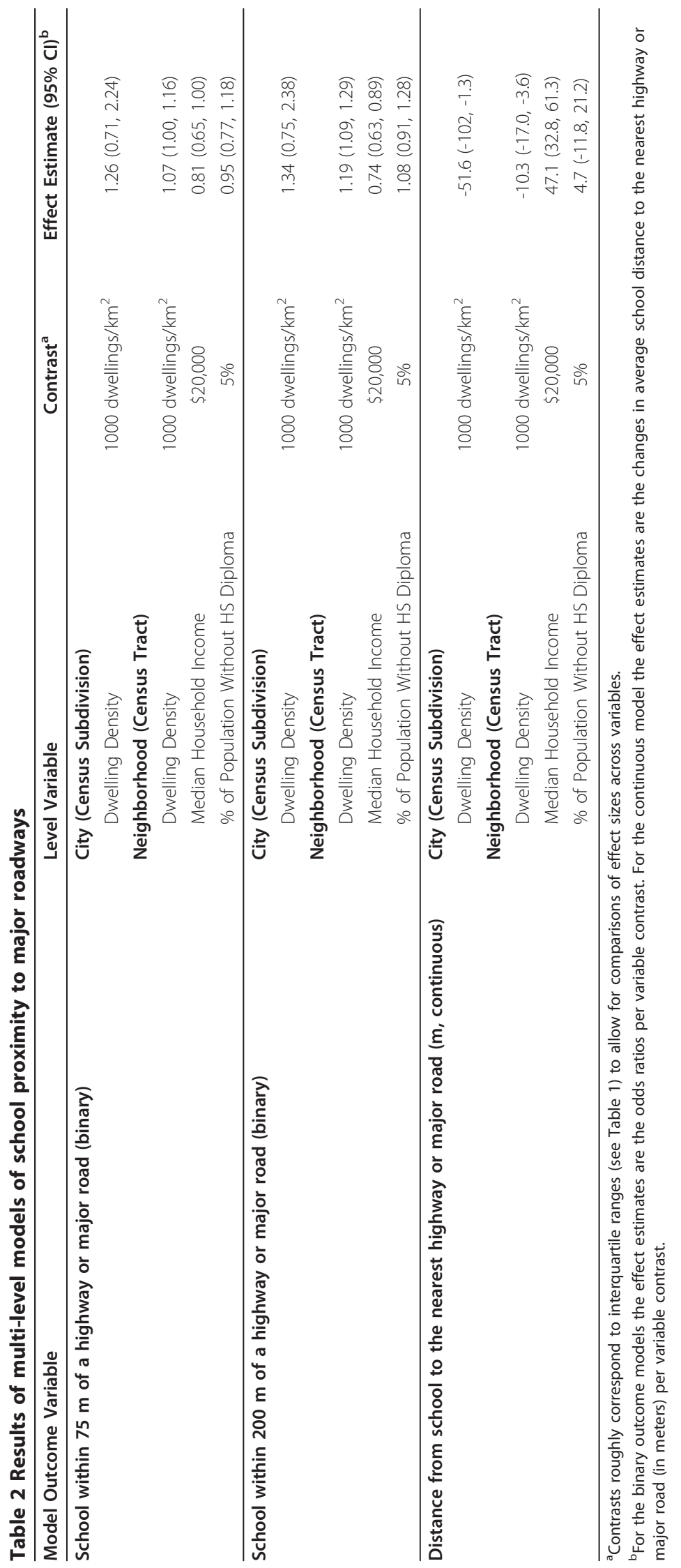


in Figure 3, which shows the percent of schools in close proximity to major roads in each city-specific neighborhood-level income quintile. Of the schools located in the poorest neighborhoods in each city, more than $22 \%$ are < $75 \mathrm{~m}$ from a major road. In the highest income quintile only $13 \%$ of schools are within $75 \mathrm{~m}$ of a major road. The same relationship with neighborhood income was observed when close proximity was defined $<200 \mathrm{~m}$ (Figure 3 ).

For the 148 schools that were manually located, the median absolute value difference in estimated major road proximity between the GPP geocoded locations and the manually determined locations was $26 \mathrm{~m}$ (range: $0-244 \mathrm{~m}$ ). In general, the automated geocoding procedure resulted in similar road proximity (median distance: $89 \mathrm{~m}$; range: $1-200 \mathrm{~m}$ ) as the manual procedure (median distance: $81 \mathrm{~m}$; range: $6-301 \mathrm{~m}$ ). When dichotomizing the 148 schools as $<75 \mathrm{~m}$ or $\geq 75 \mathrm{~m}$ from the nearest major road, 119 schools (80\%) were placed in the same category by both methods (Table 3 ). Of the 71 schools automatically geolocated within $75 \mathrm{~m}$ of a major road by GPP, 79\% were actually within $75 \mathrm{~m}$ of a major road, $87 \%$ were actually within 100 m, 90\% were actually within $150 \mathrm{~m}$, and $97 \%$ were actually within $200 \mathrm{~m}$.

\section{Discussion}

We found that $16.3 \%$ of schools in Canada's 10 largest cities were located within $75 \mathrm{~m}$ of a highway or major road. To our knowledge this is the first such study outside of the US. Unlike previous studies of schools' proximities to major roads, we used measurement data to demonstrate a clear relationship between proximity to major roads and elevated levels of traffic-related noise and air pollution, and defined close proximity based on those measurements. A growing body of epidemiologic evidence links

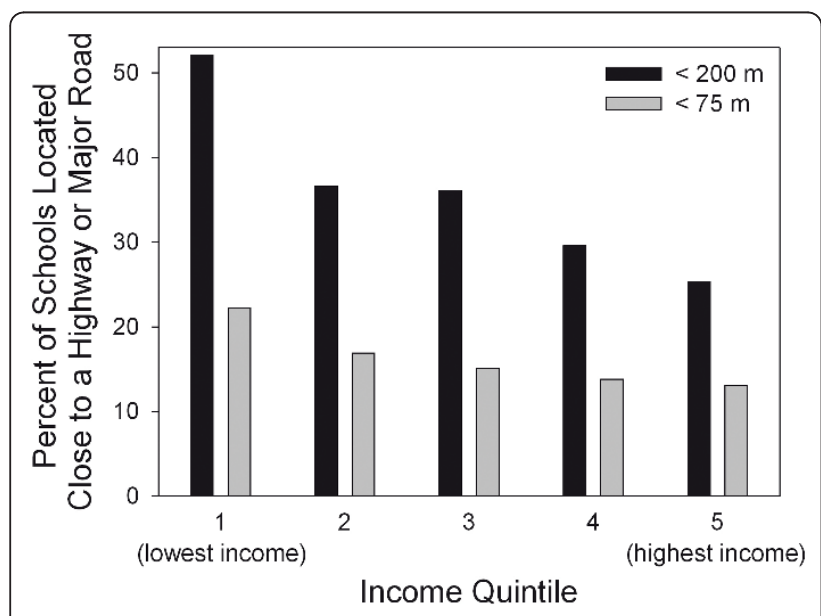

Figure 3 Percent of public elementary schools that are located close to a highway or major road by city-specific quintile of median neighborhood-level income at the school location. chronic exposure to traffic-related air pollution and noise with a wide range of health effects in children [1-6,13,35]. Thus, poorly sited schools may be placing a sizable fraction of Canadian public elementary school students at increased risk of adverse health effects. In addition, there is evidence that both noise [36,37] and air pollution [38] at schools may negatively affect academic performance.

Several studies have examined schools' proximities to major roads in the US. A study in California found that approximately $7.2 \%$ and $2.3 \%$ of public schools were within $150 \mathrm{~m}$ of medium (25,000-49,999 vehicles/day) and high traffic ( $\geq 50,000$ vehicles/day) roads, respectively [23]. A similar study in Detroit found that $4.9 \%$ of schools were within $150 \mathrm{~m}$ of high traffic ( $\geq 50,000$ vehicles/day) roads [22]. These results are generally consistent with our finding that $4.7 \%$ of schools were within $200 \mathrm{~m}$ of an expressway or principal highway. Most recently, Appatova et al. calculated roadway proximities for public schools in 9 major US cities and reported that $33 \%$ of schools were within $400 \mathrm{~m}$ of a major roadway (defined as federal interstate, US highway, or state highway) and nearly $12 \%$ were within $100 \mathrm{~m}$ [21].

Instead of using traffic volumes we defined major roads using the DMTI road classification scheme, which is standardized for roads across Canada. Although road categories are imperfect surrogates for pollution concentrations due to variability in traffic flows, vehicle types, and pollution emissions, our decision to define major roads using DMTI categories was supported by clear relationships with measured NO, ultrafine particles, and noise in 3 Canadian cities. A study in Vancouver found that roads in DMTI categories 1-4 (our definition of "major road") had mean daily traffic counts of 114,000 , $21,000,18,000$, and 15,000 vehicles/day, respectively [28]. Our choice to define close proximity as only $<75 \mathrm{~m}$ from a major road for our primary analysis was more conservative than previous studies.

Our finding that neighborhood-level income correlated with school proximity to major roads has important environmental justice implications and is consistent with several previous studies indicating a relationship between socioeconomic status and environmental quality around schools. For example, Green et. al. [23] found that several indicators of lower socioeconomic status - including percentage of students receiving reduced-price meals at school, percentage of census tract population with income below poverty level, and percentage of census tract population with no high school diploma - were positively associated with traffic within 150 meters of schools in California. Similarly, Wu et al. [22] found that students attending schools near high traffic roads in and around Detroit were more likely to be ethnic minorities and to reside in a low-income area. A study in Sweden reported an inverse correlation between $\mathrm{NO}_{2}$ concentrations 
Table 3 Comparison between GeoPinPoint geocoding and manual locating for a random subset of schools

\begin{tabular}{|c|c|c|c|c|}
\hline \multirow[b]{2}{*}{$\begin{array}{l}\text { Distances Based on GeoPinPoint } \\
\text { Geocodes }\end{array}$} & \multicolumn{4}{|c|}{ Distances Based on Google Maps Geocodes } \\
\hline & $\begin{array}{c}\text { Number (\%) of Schools < } \\
75 \mathrm{~m} \\
\end{array}$ & $\begin{array}{c}\text { Number (\%) of Schools } 75- \\
100 \mathrm{~m} \\
\end{array}$ & $\begin{array}{c}\text { Number (\%) of Schools > } \\
100 \mathrm{~m}\end{array}$ & Totals \\
\hline \multirow[t]{2}{*}{ Number (\%) of Schools $<75 \mathrm{~m}$} & 56 & 6 & 9 & 71 \\
\hline & $(38 \%)$ & $(4 \%)$ & $(6 \%)$ & $(48 \%)$ \\
\hline \multirow[t]{2}{*}{ Number (\%) of Schools $75-100 \mathrm{~m}$} & 5 & 1 & 2 & 8 \\
\hline & $(3 \%)$ & $(1 \%)$ & $(1 \%)$ & $(5 \%)$ \\
\hline \multirow[t]{2}{*}{ Number (\%) of Schools > $100 \mathrm{~m}$} & 9 & 9 & 51 & 69 \\
\hline & $(6 \%)$ & $(6 \%)$ & $(34 \%)$ & $(47 \%)$ \\
\hline \multirow[t]{2}{*}{ Totals } & 70 & 16 & 62 & 148 \\
\hline & $(47 \%)$ & $(11 \%)$ & $(42 \%)$ & $(100 \%)$ \\
\hline
\end{tabular}

outside schools and neighborhood income [39]. Houston et al. reported that child care facilities in disadvantaged areas in California were more likely to be situated near busy roads than facilities in more affluent areas [40].

Unfortunately, our data did not enable us to investigate the chronology of school and road construction and neighborhood-level income changes, and more research is needed to understand the underlying causes of our findings. For example, it might be useful to explore whether low-income residents are drawn to neighborhoods with schools close to roads (e.g., due to lower housing prices), or if low-income neighborhoods are more likely to have schools and roads constructed in close proximity to one another (e.g., due to low-income residents having less influence on community decision-making) [41].

The relationship between neighborhood dwelling density and proximity demonstrates the challenge in balancing the health risks of environmental pollution with the potential benefits of urban living. Dwelling density and other indicators of urban "compactness" are often seen as desirable due to associations with increased physical activity $[42,43]$ and decreased risks of obesity and associated morbidities [44-47]. However, our results and others' suggest that density may also lead to increases in exposure to environmental pollution. For example, Marshall et al. [48] found that Vancouver neighborhoods with a high walkability score (based on residential density, intersection density, retail floor area ratio, and land use mix) tended to also have relatively high levels of NO.

We did not find a strong east-west gradient in the fraction of schools located close to busy roads. This finding differs from the results of Appatova et al. [21] in the US. Their finding of a strong east-west gradient was driven primarily by schools on the "urban fringe" and they did not find a clear gradient for schools in urban centers. Thus, the lack of a clear gradient in our study may be due, in part, to our exclusion of suburban communities.

While this study provides the first assessment of schools' proximities to major roads outside of the US, some limitations should be noted. A 2007 study estimated that the median error for geocoded school addresses was $41 \mathrm{~m}$, with larger errors in rural locations [27]. Location errors can be exacerbated by the large footprint of school buildings and surrounding playgrounds. In our assessment based on manually locating $10 \%$ of schools we found that the median error in estimated major road proximity was $26 \mathrm{~m}$. However, the influence of location errors on our conclusions is minimized by our conservative choice of < $75 \mathrm{~m}$ as the distance of primary interest. In reality, the area of impact for vehicle emissions may extend out to $500 \mathrm{~m}$ depending on the specific pollutant [14]. We were encouraged that $87 \%$ of schools geocoded within $75 \mathrm{~m}$ a major road were actually within $100 \mathrm{~m}$, while $90 \%$ were actually within $150 \mathrm{~m}$. An additional benefit of our conservative definition of close proximity was that it reduced the influence of representing schools as points. As schools' sizes and layouts vary, the placement of classrooms and playgrounds in relation to roads can also affect students' exposures to traffic-related pollutants. Ideally, we would have overlaid the road network on a layer representing school footprints as polygons to calculate the portion of each school that is located in close proximity to a major road.

An additional limitation is that since schools data were not available from a single provider we relied on publicly available online data for this analysis, and this may have not captured all schools. In addition, data for private schools were not available or were incomplete for several cities, so this analysis included only public schools. However, while we may be missing some elementary schools in these cities, it seems unlikely that the roadway proximities of the missing schools would be systematically different from the included schools, and thus it is doubtful that our main findings and conclusions would be altered substantially by missing data. We only included schools within the census subdivision boundaries for major Canadian cities. Our sensitivity analysis suggested that, in general, schools in suburban communities were less frequently located in close proximity to major roads. Therefore, our results cannot be extrapolated outside of the 
cities included in this analysis. Nevertheless, since we included the 10 largest Canadian cities, which account for nearly one third of the Canadian population, our results apply to a large proportion of Canadian elementary students. Finally, we only considered the school environment, but other microenvironments and activities may make substantial contributions to the air pollution and noise exposures of school-aged children. For example, children can receive high exposures to some pollutants while commuting on diesel school buses [49], although exposures depend on a wide range of factors including emissions controls [50], fuels [51,52], and routes [52]. The relationship between school location and students' exposures is complicated by the fact that school location may affect accessibility and the amount of time that students spend in transit. In addition, attending a school located near a major road may also influence health by discouraging walking and cycling to school [53].

There are several possibilities for minimizing students' air pollution and noise exposures in and around schools. Concentrations of traffic-related air pollution can be reduced both by technical improvements that reduce per-vehicle emissions, such as improved engine efficiency, and urban planning/policy efforts that reduce automobile use, such as public transit enhancements and improvements in cycling infrastructure. New schools could be set back from major traffic corridors, and it may also be beneficial to orient the school facilities such that the outdoor playgrounds are located as far as possible from major roads [54]. For example, California State Bill 352 requires health risk assessments to be conducted for proposed school sites that are within $150 \mathrm{~m}$ of a busy roadway [55], while legislation in New Jersey (Assembly Bill 856, which was motivated by safety concerns and not environmental pollution) forbids the construction of new highway ramps within $300 \mathrm{~m}$ of an existing school [56]. The importance of traffic-related pollution in school siting decisions is also gaining recognition in Canada. For example, the British Columbia Ministry of Environment recommends that schools and other sensitive facilities be placed at least $150 \mathrm{~m}$ from roads with over 15,000 vehicles/day [57]. Given the small spatial scales over which traffic-related air pollutants and noise vary, shifting school locations by relatively small distances could result in substantial reductions in students' exposures, health risks, and impacts on academic performance.

There are also several potential strategies for reducing exposures at existing schools. As part of New York City's Asthma Free School Zone Project, Richmond-Bryant et al. [58] evaluated relationships between pollution concentrations and vehicle traffic and idling during school dismissal periods. They concluded that programs focused on school bus idling and redirecting school bus traffic could have small but measurable effects on diesel soot concentrations near schools. Some communities have implemented programs that limit outdoor activities during high outdoor air pollution days [59], but these programs are likely to be more effective for highly temporally variable pollutants like ozone than for traffic related pollutants, which are consistently elevated near roads. Another possible strategy is to modify school facilities. For example, the Port of Long Beach in California has created a "Schools and Related Sites Grant Program" in which schools and daycare facilities in close proximity to the Port may apply for funding to mitigate air pollution and noise impacts through improvements such as installing high efficiency particulate air (HEPA) filters in ventilation systems, replacing window and door seals, constructing sound barriers, and installing double glazed windows [60].

\section{Conclusion}

We conducted the first assessment of schools' proximities to major roads outside of the US and found that $16 \%$ of public elementary schools were located within $75 \mathrm{~m}$ of highways or major roads. We conservatively chose $75 \mathrm{~m}$ as the distance of interest based on measurements of traffic-related air and noise pollution in 3 Canadian cities with different characteristics. There was considerable variability between cities in the percentage of schools located near roads, and distance to the nearest highway or major road was correlated with neighborhood income and inversely correlated with neighborhood dwelling density. In the lowest quintile of neighborhood income, $22 \%$ of schools were located within $75 \mathrm{~m}$ of a highway or major road. A substantial fraction of students at public elementary schools in Canada, particularly students attending schools in low income neighborhoods, may be exposed to elevated levels of air pollution and noise while at school. As a result, the school environment may negatively impact the academic performance and healthy development of a large number of Canadian children.

\section{Additional material}

Additional file 1: Data sources for school locations and

characteristics. The table provides the websites used to obtain school addresses.

\section{Acknowledgements}

We would like to thank those who collected the air pollution and noise data. We are also grateful to Dr. Winnie Chu and her staff for analyzing $\mathrm{NO}_{\mathrm{x}}$ samples.

\section{Competing interests}

The authors declare that they have no competing interests. 


\section{Authors' contributions}

OA and RWA designed the study and drafted the manuscript. RA, MB, and $\mathrm{HD}$ designed the pollution measurement studies, and RA supervised collection of ultrafine particle data. All authors contributed to the interpretation of data, and read and approved the final manuscript

\section{Author details}

'Department of Geography, Simon Fraser University, Burnaby, BC, Canada. ${ }^{2}$ School of Population and Public Health, The University of British Columbia, Vancouver, BC, Canada. ${ }^{3}$ Faculty of Health Sciences, Simon Fraser University, Burnaby, BC, Canada.

Received: 29 September 2011 Accepted: 21 December 2011

Published: 21 December 2011

\section{References}

1. Brunekreef $B$, Janssen NAH, deHartog J, Harssema $H$, Knape $M$, vanVliet $P$ : Air pollution from truck traffic and lung function in children living near motorways. Epidemiology 1997, 8:298-303.

2. Gauderman WJ, Vora H, McConnell R, Berhane K, Gilliland F, Thomas D, Lurmann F, Avoli E, Kunzli N, Jerrett M, Peters J: Effect of exposure to traffic on lung development from 10 to 18 years of age: a cohort study. Lancet 2007, 369:571-577.

3. Clark NA, Demers PA, Karr CJ, Koehoorn M, Lencar C, Tamburic L, Brauer M: Effect of early life exposure to air pollution on development of childhood asthma. Environ Health Perspect 2010, 118:284-290.

4. Brauer M, Gehring U, Brunekreef B, de Jongste J, Gerritsen J, Rovers M, Wichmann HE, Wijga A, Heinrich J: Traffic-related air pollution and otitis media. Environ Health Perspect 2006, 114:1414-1418.

5. Suglia SF, Gryparis A, Wright RO, Schwartz J, Wright RJ: Association of black carbon with cognition among children in a prospective birth cohort study. Am J Epidemiol 2008, 167:280-286.

6. Paunovic K, Stansfeld S, Clark C, Belojevic G: Epidemiological studies on noise and blood pressure in children: Observations and suggestions. Environment International 2011, 37:1030-1041.

7. Ohrstrom E, Hadzibajramovic E, Holmes M, Svensson H: Effects of road traffic noise on sleep: Studies on children and adults. Journal Of Environmental Psychology 2006, 26:116-126.

8. Clark C, Martin R, van Kempen E, Alfred T, Head J, Davies HW, Haines MM, Barrio IL, Matheson M, Stansfeld SA: Exposure-effect relations between aircraft and road traffic noise exposure at school and reading comprehension - The RANCH project. Am J Epidemiol 2006, 163:27-37.

9. Klepeis NE, Nelson WC, Ott WR, Robinson JP, Tsang AM, Switzer P, Behar JV, Hern SC, Engelmann WH: The National Human Activity Pattern Survey (NHAPS): a resource for assessing exposure to environmental pollutants. $J$ Expo Anal Environ Epidemiol 2001, 11:231-252

10. Leech JA, Nelson WC, Burnett RT, Aaron S, Raizenne ME: It's about time: A comparison of Canadian and American time-activity patterns. J Expo Anal Environ Epidemiol 2002, 12:427-432.

11. Allen RW, Davies H, Cohen MA, Mallach G, Kaufman JD, Adar SD: The spatial relationship between traffic-generated air pollution and noise in 2 US cities. Environ Res 2009, 109:334-342.

12. Zhu YF, Hinds WC, Kim S, Sioutas C: Concentration and size distribution of ultrafine particles near a major highway. J Air Waste Manag Assoc 2002, 52:1032-1042.

13. HEl: Health Effects Institute Special Report 17, Traffic Related Air Pollution: A Critical Review of the Literature. 2010

14. Zhou Y, Levy Jl: Factors influencing the spatial extent of mobile source air pollution impacts: a meta-analysis. BMC Public Health 2007, 7.

15. Beckerman $B$, Jerrett $M$, Brook JR, Verma DK, Arain MA, Finkelstein MM: Correlation of nitrogen dioxide with other traffic pollutants near a major expressway. Atmos Environ 2008, 42:275-290.

16. Van Roosbroeck S, Jacobs J, Janssen NAH, Oldenwening M, Hoek G, Brunekreef B: Long-term personal exposure to PM2.5, soot and NOx in children attending schools located near busy roads, a validation study. Atmos Environ 2007, 41:3381-3394.

17. Diapouli $E$, Chaloulakou A, Spyrellis N: Levels of ultrafine particles in different microenvironments - Implications to children exposure. Sci Total Environ 2007, 388:128-136

18. Guo H, Morawska L, He CR, Zhang YLL, Ayoko G, Cao M: Characterization of particle number concentrations and $\mathrm{PM}(2.5)$ in a school: influence of outdoor air pollution on indoor air. Environmental Science And Pollution Research 2010, 17:1268-1278.

19. Roorda-Knape MC, Janssen NAH, de Hartog JJ, van Vliet PHN, Harssema $H_{\text {, }}$ Brunekreef B: Air pollution from traffic in city districts near major motorways. Atmos Environ 1998, 32:1921-1930.

20. Janssen NAH, van Vliet PHN, Aarts F, Harssema H, Brunekreef B: Assessment of exposure to traffic related air pollution of children attending schools near motorways. Atmos Environ 2001, 35:3875-3884.

21. Appatova AS, Ryan PH, LeMasters G, Grinshpun SA: Proximal exposure of public schools and students to major roadways: a nationwide US survey. Journal of Environmental Planning and Management 2008, 51:631-646.

22. Wu Y-C, Batterman SA: Proximity of schools in Detroit, Michigan to automobile and truck traffic. Journal Of Exposure Science And Environmental Epidemiology 2006, 16:457-470.

23. Green RS, Smorodinsky S, Kim JJ, McLaughlin R, Ostro B: Proximity of California public schools to busy roads. Environ Health Perspect 2004 112:61-66

24. Chakraborty J, Zandbergen PA: Children at risk: measuring racial/ethnic disparities in potential exposure to air pollution at school and home. $J$ Epidemiol Community Health 2007, 61:1074-1079.

25. Aurini J, Davies S: The transformation of private tutoring: Education in a franchise form. Canadian Journal Of Sociology-Cahiers Canadiens De Sociologie 2004, 29:419-438.

26. Bonner MR, Han D, Nie J, Rogerson P, Vena JE, Freudenheim AL: Positional accuracy of geocoded addresses in epidemiologic research. Epidemiology 2003, 14:408-412.

27. Zandbergen PA, Green JW: Error and bias in determining exposure potential of children at school locations using proximity-based GIS techniques. Environ Health Perspect 2007, 115:1363-1370.

28. Setton EM, Hystad PW, Keller PC: Road Classification Schemes - Good Indicators of Traffic Volume? University of Victoria Spatial Sciences Laboratories Working Paper 2005, 05-014.

29. Allen RW, Amram O, Wheeler AJ, Brauer M: The Transferability of NO and NO2 Land Use Regression Models Between Cities and Pollutants. Atmos Environ 2011, 45:369-378

30. Henderson SB, Beckerman B, Jerrett M, Brauer M: Application of land use regression to estimate long-term concentrations of traffic-related nitrogen oxides and fine particulate matter. Environmental Science \& Technology 2007, 41:2422-2428.

31. Abernethy R, McKendry I, Allen R, Brauer M: Developing a Land Use Regression Model for Ultrafine Particle Concentrations in Vancouver, Canada. Environ Health Perspect 2011, Available online, http://ehp03.niehs. nih.gov/article/fetchArticle.action?articleURl=info:doi/10.1289/ehp.isee2011.

32. Davies HW, Vlaanderen JJ, Henderson SB, Brauer M: Correlation between coexposures to noise and air pollution from traffic sources. Occup Environ Med 2009, 66:347-350

33. Ross NA, Tremblay S, Khan S, Crouse D, Tremblay M, Berthelot J-M: Body mass index in urban Canada: Neighborhood and metropolitan area effects. Am J Public Health 2007, 97:500-508.

34. Census Canada: Population and dwelling counts for census metropolitan areas and census agglomerations.[http://dc1.chass.utoronto.ca/census/ 2006/index.html].

35. Babisch W: Transportation noise and cardiovascular risk: Updated Review and synthesis of epidemiological studies indicate that evidence has increased. Noise \& Health 2006, 8:1-29.

36. Shield BM, Dockrell JE: The effects of environmental and classroom noise on the academic attainments of primary school children. $J$ Acoust Soc Am 2008, 123:133-144.

37. Sanz SA, Garcia AM, Garcia A: Road Traffic Noise Around Schools - A Risk For Pupils Performance. Int Arch Occup Environ Health 1993, 65:205-207.

38. Mohai P, Kweon B-S, Lee S, Ard K: Air Pollution Around Schools Is Linked To Poorer Student Health And Academic Performance. Health Aff (Millwood) 2011, 30:852-862.

39. Chaix B, Gustafsson S, Jerrett M, Kristersson H, Lithman T, Boalt A, Merlo J: Children's exposure to nitrogen dioxide in Sweden: investigating environmental injustice in an egalitarian country. J Epidemiol Community Health 2006, 60:234-241.

40. Houston D, Ong P, Wu J, Winer A: Proximity of licensed child care facilities to near-roadway vehicle pollution. Am J Public Health 2006, 96:1611-1617. 
41. Schweitzer L, Valenzuela A: Environmental injustice and transportation: The claims and the evidence. Journal Of Planning Literature 2004, 18:383-398.

42. Saelens BE, Sallis JF, Frank LD: Environmental correlates of walking and cycling: Findings from the transportation, urban design, and planning literatures. Ann Behav Med 2003, 25:80-91.

43. Frank LD, Schmid TL, Sallis JF, Chapman J, Saelens BE: Linking objectively measured physical activity with objectively measured urban form Findings from SMARTRAQ. Am J Prev Med 2005, 28:117-125.

44. Zhao ZX, Kaestner R: Effects of urban sprawl on obesity. J Health Econ 2011, 29:779-787.

45. Ewing R, Schmid T, Killingsworth R, Zlot A, Raudenbush S: Relationship between urban sprawl and physical activity, obesity, and morbidity. Am J Health Promot 2003, 18:47-57.

46. Ewing R, Brownson RC, Berrigan D: Relationship between urban spraw and weight of United States youth. Am J Prev Med 2006, 31:464-474.

47. Lopez R: Urban sprawl and risk for being overweight or obese. Am J Public Health 2004, 94:1574-1579.

48. Marshall JD, Brauer M, Frank LD: Healthy Neighborhoods: Walkability and Air Pollution. Environ Health Perspect 2009, 117:1752-1759.

49. Behrentz E, Sabin LD, Winer AM, Fitz DR, Pankratz DV, Colome SD, Fruin SA: Relative importance of school bus-related microenvironments to children's pollutant exposure. J Air Waste Manag Assoc 2005, 55:1418-1430.

50. Trenbath K, Hannigan MP, Milford JB: Evaluation of retrofit crankcase ventilation controls and diesel oxidation catalysts for reducing air pollution in school buses. Atmos Environ 2009, 43:5916-5922.

51. Mazzoleni C, Kuhns HD, Moosm ller H, Witt J, Nussbaum NJ, Chang MCO, Parthasarathy G, Nathagoundenpalayam SKK, Nikolich G, Watson JG: A case study of real-world tailpipe emissions for school buses using a 20\% biodiesel blend. Sci Total Environ 2007, 385:146-159.

52. Sabin LD, Kozawa K, Behrentz E, Winer AM, Fitz DR, Pankratz DV, Colome SD, Fruin SA: Analysis of real-time variables affecting children's exposure to diesel-related pollutants during school bus commutes in Los Angeles. Atmos Environ 2005, 39:5243-5254.

53. O'Loghlen S, Pickett W, Janssen I: Active Transportation Environments Surrounding Canadian Schools. Canadian Journal Of Public Health-Revue Canadienne De Sante Publique 2011, 102:364-368.

54. Rundell KW, Caviston R, Hollenbach AM, Murphy K: Vehicular air pollution, playgrounds, and youth athletic fields. Inhal Toxicol 2006, 18:541-547.

55. State of California: State Bill Number 352.[http://info.sen.ca.gov/pub/03-04/ bill/sen/sb_0351-0400/sb_352_bill_20031003_chaptered.html].

56. State of New Jersey: Assembly Bill No. 856.[http://www.njleg.state.nj.us/ 2006/Bills/PL07/308_.PDF].

57. British Columbia Ministry of Environment: Environmental Best Management Practices for Urban and Rural Land Development in British Columia.[http://www.bcairquality.ca/reports/pdfs/aqbmps_feb16_06.pdf].

58. Richmond-Bryant J, Saganich C, Bukiewicz L, Kalin R: Associations of PM (2.5) and black carbon concentrations with traffic, idling, background pollution, and meteorology during school dismissals. Sci Total Environ 2009, 407:3357-3364

59. Shendell DG, Rawling MM, Foster C, Bohlke A, Edwards B, Rico SA, Felix J, Eaton S, Moen S, Roberts EM, Love MB: The outdoor air quality flag program in central california: A school-based educational intervention to potentially help reduce children's exposure to environmental asthma triggers. J Environ Health 2007, 70:28-31.

60. Port of Long Beach: Schools and Related Sites Grant Program.[http:// www.polb.com/environment/grants/schools.asp].

doi:10.1186/1476-072X-10-68

Cite this article as: Amram et al.: Proximity of public elementary schools to major roads in Canadian urban areas. International Journal of Health Geographics 2011 10:68.

\section{Submit your next manuscript to BioMed Central and take full advantage of:}

- Convenient online submission

- Thorough peer review

- No space constraints or color figure charges

- Immediate publication on acceptance

- Inclusion in PubMed, CAS, Scopus and Google Scholar

- Research which is freely available for redistribution

Submit your manuscript at www.biomedcentral.com/submit
Ciomed Central 